\title{
Organogenic nodule formation from hop internodes. Reactive oxygen species and expression of lipoxygenase and extracellular-regulated kinases
}

\author{
Ana M Fortes*1, Marta Sousa Silva*1, Joana Costa1 ${ }^{1}$, Maria José Coronado ${ }^{2}$, \\ Pilar S Testillano ${ }^{2}$, Maria del Carmen Risueco ${ }^{2}$ and Maria S Pais ${ }^{1}$
}

\author{
Address: ${ }^{1}$ Lab of Plant Biotechnology, Ed ICAT, Faculdade de Ciéncias, Universidade Lisboa, Lisboa, Portugal and ${ }^{2}$ Plant Development and Nuclear \\ Organization Group, Centro de Investigaciones Biologicas, CSIC, Madrid, Spain \\ * Corresponding authors
}

from Cell Biology of Nitric Oxide and Cell Death in Plants

Yalta, Ukraine, 8-II September 2004

Published: 31 May 2005

BMC Plant Biology 2005, 5(SuppI I):SI6 doi:I0.I I86/I47I-2229-5-SI-SI6
Organogenic nodules have been studied in several plant species as an additional morphogenic pathway for regeneration strategies, automated micropropagation, and genetic transformation for desirable characteristics. This process has been described in hop [1].

Lipoxygenases (LOX) have several functions in plants such as response to wounding stress and pathogen attack, and growth and development [2]. Western blotting analysis showed a de novo synthesis of LOXs isoenzymes in response to wounding and during development of nodules. Immunogold labelling detected LOX in peroxisomes of some nodular cells, probably related to programmed degradation of these organelles [3]. Nodule separation into "daughter nodules" was initiated by the formation of necrotic layers at the future region of nodule separation which accumulated reactive oxygen species (ROS) as revealed by NBT staining. Peroxisomes may have a function in plant cells as a source of signal molecules like nitric oxide and superoxide radicals [4]. Low levels of nitric oxide and ROS are involved in many physiological processes, including growth and development [4]. Preliminary studies showed that internodes cultured with $0.3 \mathrm{mM}$ of $\mathrm{N}$-acetylcysteine, an inhibitor of ROS, did not undergo nodule formation. LOX presence in peroxisomes may act as a source of ROS.

MAPK homologues belonging to the Extracellular-Regulated Kinases cascade were active either in the nucleus or cytoplasm depending on cellular type and developmental stage of nodule formation. ERK2 was activated upon wounding of internodes, apparently due to the formation of reactive oxygen species. ERK1 expression increased during nodule formation and plantlet regeneration [5]. During prenodule formation, ERKs were detected in the cytoplasm and nucleus of dividing cells, co-localizing with activated MAPKs. The presence of ERKs in the nucleus of prenodular cells may be related to the initiation of cell differentiation into nodules. Prenodules showed elevated levels of ROS. In vacuolated cells of nodules, ERK1/2 appeared in the cytoplasm and nucleus whereas in meristematic nodular cells they appeared only in the cytoplasm. These different cellular localization patterns may be related to proliferation and/ or differentiation processes occurring during organogenic nodule formation.

\section{References}

I. Fortes AM, Pais MS: Am J Bot 2000, 87:971-979.

2. Feussner I, Wasternack C: Annu Rev Plant Biol 2002, 53:275-297.

3. Fortes AM, et al.: J Histochem Cytochem 2004, 52(2):227-24I.

4. del Río LA, et al.: J Exp Bot 2002, 53(372): I 255-I272.

5. Silva MF, et al.: Eur J Cell Biol 2004 in press. 